\title{
1943. Don Quijote sebastianizado. En un lugar de Europa, que el autor quiso poner Tristiânia
}

\author{
Maria Fernanda de Abreu*
}

\section{LA SEBASTIANIZACIÓN DE DON QUIJOTE EN LA LITERATURA PORTUGUESA**}

Hace ya algo más de dos décadas, al estudiar la recepción de Cervantes en el romanticismo portugués, me encontré con un uso de la figura de Don Quijote en la literatura y en el ensayismo en Portugal que entonces señalé como, probablemente, la más característica especificidad de aquella recepción en el contexto de las demás recepciones europeas del personaje cervantino. Fue lo que entonces llamé «sebastianización» de Don Quijote o «quijotización de Don Sebastião», ya que consistía, fundamentalmente, en la fusión o convergencia de ambas figuras (Abreu, 1994a y 1994b).

Había podido registrar el fenómeno en los años 70 del siglo XIX, elaborado por figuras tan destacadas del pensamiento y de la literatura como Pinheiro Chagas o Guerra Junqueiro. Asimismo, pude igualmente observar cómo aquél seguía manifestándose a lo largo del siglo XX, por lo menos hasta los años 50 . Se trataba de una elaboración realizada siempre bajo el peso determinante de ciertos contextos históricos e ideológicos, de crisis político-social y/o identitaria. Así, por ejemplo, romántico finisecular, Pinheiro Chagas había hermanado ambas figuras, el caballero manchego y el rey, en la locura, la castidad y la fe caballeresca. Teixeira de Pascoais, en 1911, embreñado en sus tesis sobre el

** Para el uso del verbo poner en este título, se remite al final del Quijote: «...cuyo lugar no quiso poner Cide Hamete puntualmente...» (II, 74). 
saudosismo como elemento identitario esencial de lo portugués, había hecho algo semejante. Y, más tarde, en tiempos de la Guerra Civil española, J. Gomes Ferreira -a pesar de su ideología marxista-comunista, en apariencia tan opuesta a las de aquellos otros escritores- juntó a ambos, al rey y al caballero, en el mitema de la neblina, tal como antes lo hiciera Pascoais ${ }^{1}$.

La obra que ahora me propongo presentar formaba ya parte de ese corpus, pero la verdad es que no he llegado jamás a dedicarle siquiera una página. $\mathrm{O}$ porque no pertenecía, cronológicamente, al romanticismo o porque habría que dedicar el análisis a unos cuantos textos más, siempre en un espacio y tiempo $\operatorname{acotados}^{2}$. No pertenecía al romanticismo, si consideramos a éste como un periodo literario strictu senso, habría que precisar, ya que es muy posible que esta apropiación «sebastianista» de Don Quijote sea, de raíz, o de herencia, aún y siempre, de naturaleza romántica. Pero dejémoslo, ya que esto nos llevaría por otros caminos... y recordemos en qué consiste el «sebastianismo».

Centrado en la figura del rey Dom Sebastião, desaparecido en la batalla de Alcácer-Quibir, y causa entre otras de que Portugal perdiera, entonces, su independencia, pasando así a formar parte del reino de España, en el sebastianismo se apoya una de las más persistentes mitologías mesiánicas de la historia política y cultural de Portugal y de su imaginario. Recuperando la figura del «encubierto» y reconfigurada en torno al rey desaparecido, y no muerto, aquella presenta como mitema basilar «la neblina». El rey, escondido en una isla, volverá en un caballo blanco, salido de las olas marítimas, en una mañana de neblina (uma manhã de nevoeiro), para salvar a la patria y al pueblo.

Enlaza, además, con mitos mesiánicos anteriores, entre ellos el del Encubierto, por un lado, y se apropia de las profecías presentes en las coplas de Bandarra (1500-1556), un poeta popular que anunciaba la llegada de un Mesías libertador, que instauraría el Quinto Imperio.

Bien vivo el mito, desde finales del siglo XVI hasta nuestros días, siempre con una fortuna que los avatares históricos y políticos no han dejado de alimentar, a él se recurre una y otra vez. La bibliografía sebastianista, tanto en el campo de la creación literaria como en el campo ensayístico, es ingente, ya sea para exaltarlo o para denostarlo, no raras veces por vía paródica.

Fernando Pessoa, cuyo libro de poemas Mensagem constituye una de las más elaboradas y exaltadas recreaciones del mito, en unas notas reflexivas, intenta una definición. Esto dice Pessoa (escrito quizás a mediados de los años veinte), en traducción de Ángel Crespo:

¿Qué es, fundamentalmente, el sebastianismo? Es un movimiento religioso, formado en torno a una figura nacional, en el sentido de un mito.

1. Tal desconcierto me causó aquel descubrimiento que a una de mis comunicaciones sobre el asunto decidí titularla «Labirintos da identidade: de como um fidalgo castelhano-manchego foi chamado a salvar a pátria portuguesa (da Literatura Comparada ao Fado Lusíada)» (Abreu, 1996).

2. Tal como em 1994, sigo considerando como no integrable en este corpus el libro de Ribeiro Colaço ([1953]). 
En sentido simbólico, Don Sebastián es Portugal: Portugal que perdió su grandeza con Don Sebastián, y que sólo volverá a tenerla con su regreso, un regreso simbólico -como si, en virtud de un misterio maravilloso y divino, su propia vida hubiese sido simbólica- pero en que no es absurdo confiar. Don Sebastián volverá, dice la leyenda, una mañana de niebla, en su caballo blanco, venido de la isla lejana donde ha estado esperando la hora de la vuelta. La mañana de niebla indica, evidentemente, un renacimiento nublado por elementos de decadencia, por restos de la Noche en que ha vivido la nacionalidad (Pessoa, 1986).

Observemos ya desde este momento que el hecho de que esta figura se haya forjado para, supuestamente, liberar a Portugal del «yugo castellano», añade un elemento interesante al hecho de fundirlo con el héroe castellano-manchego de Cervantes.

En 2002 se publicó en las ediciones de la Biblioteca Geral de Coimbra un volumen de casi 800 páginas, Sebástica. Bibliografia Geral sobre D. Sebastião, catálogo organizado por Vitor Amaral de Oliveira, rigurosísimo trabajo que constituyó su tesis de doctorado presentada en la Universidad de Montpellier, bajo la orientación del Prof. Adrien Roig. Allí se recogen 3780 piezas, publicadas no solo en Portugal sino también en España, Brasil, Francia... Recurramos a este catálogo para recordar que, aún en el siglo XVII, autores castellanos «se interesaron diferentemente por la materia sebástica»: en el teatro, Vélez de Guevara, Lope de Vega y Francisco de Villegas, dos «comedias» y una «tragedia» (la de Lope). Y mucha poesía: Fray Luis de León, Lope de Vega, Fernando Herrera, «o de maior eco, um Soneto e, em particular, a Canção 'por la pérdida de D. Sebastián', com várias traduções no século XIX [...]» (Oliveira, 2002: XXIII) ${ }^{3}$. Y es aún en el siglo XVII cuando el Padre António Vieira desarrolla en Brasil el mito sebastianista, ampliándolo con una vertiente quinto-imperialista. Vitor Amaral de Oliveira considera su Historia do Futuro junto a las Trovas de Bandarra «os dois textos mais importantes do sebastianismo» (2002: XXX).

\section{DULCINÉA OU A ÚLTIMA AVENTURA DE DOM QUIXOTE, DE CARLOS SELVAGEM ${ }^{4}$}

En este contexto del mito mesiánico y salvífico, el sebástico, interpretaremos la recreación de la figura de Don Quijote en la obra sobre la que incide este

3. Ver, en particular, la «Introdução», pp. XVII-LVIII donde, entre otras conclusiones, el autor considera que se puede «dividir as Relações e os textos históricos sobre D. Sebastião e a batalha de Alcácer-Quibir segundo as origens da sua composição: origem espanhola ou origem portuguesa. Com isto se significa o facto de difundirem uma visão dos factos do lado castelhano, ou do lado português». Y señala el «cariz autonomista» de esta historiografía lusitana. (2002: XXIV-XXV).

4. Carlos Selvagem es pseudónimo de Carlos Tavares de Andrade Afonso dos Santos (18901973). 
comentario, la cual va a proporcionarnos, en 1943, una significativa diferencia en relación a los textos anteriores, de finales del siglo XIX y primeras décadas del XX.

De hecho, lo primero que nos llama fuertemente la atención es saber que se haya representado en el Teatro Nacional Dona Maria, en enero de 1944, en plena dictadura salazarista, del llamado «Estado Novo», esta pieza de teatro en la cual un Don Quijote libertador de los oprimidos es llamado a restablecer la justicia social. Sin cualquier ambigüedad por parte de su autor, como se verá claramente, en el libro, desde su apertura.

Es la única pieza de teatro de este corpus -donde encontramos a un Don Quijote sebastianizado-y se presenta como una «Farsa heróica em 5 jornadas com 2 quadros e prólogo» ${ }^{5}$.

La puesta en escena estaba enriquecida con escenarios de uno de los más prestigiosos artistas plásticos portugueses, además de escritor, Almada $\mathrm{Ne}$ greiros. Y acompañada con música de Ernesto Halffter. Precisamente, por vía de la música del compositor español, entonces exiliado en Lisboa, tiene la obra una excepcional fortuna crítica en el cervantismo español. Así, por ejemplo, Germán Gan Quesada (2007), al estudiar las «Variaciones sobre el tema cervantino en la música de la familia Halffter», en el apartado sobre «Don Quijote de La Mancha y sus enamoradas», le dedica varias páginas al estudio de la música que acompaña a la obra y a la reconstitución de la pieza.

«Nos ha sido imposible, pese a una prolongada pesquisa, dar con la partitura de esta música escénica» (Gan Quesada, 2007: 380), asegura el musicólogo y compositor español, autor de este minucioso estudio. Pero al observar que, «sin embargo, el estudio de la pieza teatral y de un notable aparato bibliográfico permite la reconstrucción» de la naturaleza y características de dicha música escénica, siguiendo a par y paso el texto de la pieza, y reconociendo que «las numerosas acotaciones escénicas relacionadas con la materia» revelan que «la participación de la música en el drama es constante», llegará a proponer una rigurosa correspondencia entre jornadas, escenas, cuadros, estrofas en algunos casos, y su «contrapunto musical» de la autoría de Ernesto Halffter. Dichas acotaciones indican, además, con minucia, en cada momento, los instrumentos y los géneros musicales adecuados. Lo hace también a partir de la detallada descripción de la pieza musical, tal como aparece en un artículo contemporáneo de aquella representación, publicado en un periódico de Lisboa por Santiago Kastner, «A música da peça "D.Quixote" de Ernesto Halffter» ${ }^{6}$. Finalmente, se apoya asimismo en el hecho de que el compositor haya transformado parte de su trabajo inicial en la suite Dulcinée, cuyo estudio le proporciona fuertes argumentos para la reconstrucción de la música de la pieza de Carlos Selvagem, observando, desde luego, cuando resume el argumento, «sus claros aires

5. Sobre el Quijote en el teatro portugués, ver los estudios de J. Ares Montes, Fidelino de Figueiredo e Maria Idalina Resina Rodrigues.

6. Ver más elementos sobre el artículo de S. Kastener en Gan Quesada (2007: 381-2): "la fuente más valiosa para conocer la música incidental de Halffter para Dulcinéa”. 
sebastianistas» (Gan Quesada, 2007: 379) (no conozco ningún trabajo análogo para los escenarios de Almada Negreiros y espero que algún día se haga).

Sobre la recepción coetánea de la obra, Germán Gan Quesada aporta también elementos importantes sacados de reseñas de periódicos y concluye:

Aunque la crítica teatral no se mostró demasiado convencida del logro de las intenciones simbólicas del argumento de Selvagem -y de su probable dimensión de crítica política al régimen dictatorial de Salazar- sí se apresuró a señalar lo acertado de la elección de Ernesto Halffter, «garantía de calidad», como ilustrador musical de la peripecia (Gan Quesada 2007: 381).

En la parte final, que dedicaré al autor Carlos Selvagem, referiré otras opiniones. Quiero, sin embargo, ya desde este momento, adelantar algo. En la presentación de la obra escribe el musicólogo español: «La acción de la obra teatral [...] transcurre en la república insular de Tristiânia, en un período temporal indeterminado, aunque identificable con el siglo XVII» (Gan Quesada, 2007: 379). Sería ésta, en efecto, la incertidumbre que el autor querría lanzar sobre la censura del régimen. Y en la presentación de la acción, también él escribe que la acción transcurre em tempos remotos. Pero está claro, lo estuvo para muchos espectadores, que el tiempo de la acción era el tiempo de su autor. (Por ello, destaco la fecha en el título de este ensayo). Lo estuvo también, en algún momento, para la policía del régimen que terminó por expulsarlo del ejército, donde tenía una carrera prominente, y encarcelarlo ${ }^{7}$.

\section{¿UNA FARSA HEROICA?}

Notemos, desde ya, la clasificación genérica del propio autor: farsa heróica, la única así designada en su amplia obra teatral, donde encontramos «dramas rurales» y una «comédia dramática».

La división en «jornadas» remite, desde luego, al teatro contemporáneo del Quijote. Publicada en libro, con fecha del ano de Graça de 1943, éste abre con una página donde, en epígrafe, se reproduce uno de los pasajes más inequívocos del libro cervantino. Precisamente, sacadas del episodio de los galeotes, aparecen en primer lugar las palabras «...Porque me parece duro caso -añadió Don Quijote- hacer esclavos a los que Dios y naturaleza hizo libres» hasta «y cuando de grado no lo hagáis [esto es, liberar a aquellos "pobres" hombres], esta lanza y esta espada, con el valor de mi brazo, harán que lo

7. El historiador del teatro portugués Luiz Francisco Rebello termina un texto de evocación de Carlos Selvagem en el centenario de su nacimiento, afirmando que, además de al dramaturgo, historiador y ensayista, importa recordar "sobretudo, o homem vertical e íntegro, que nunca reagiu por cálculo e, no seu altivo individualismo, soube ser solidário das grandes esperanças e das grandes cóleras nacionais - o que lhe valeu ser perseguido, preso e condenado pelo simples crime de amar e desejar, para o seu país, a liberdade e a justiça.»"(Rebello, 1991: 195). 
hagáis por fuerza». Nótese el desplazamiento a la primera frase del «añadió Don Quijote», que en el texto de Cervantes surge en la frase siguiente, pareciéndonos obvio que la función del mismo es colocar, lo antes posible, las palabras del epígrafe bajo la auctoritas de la voz quijotesca. Si quisiésemos especular un poco, no nos sería difícil imaginar aquí una señal de un proceso de identificación entre el autor Carlos Selvagem, escritor y soldado, y esta voz que, con «mansedumbre y sosiego» pide que se haga justicia (lo que él cree ser la justicia), a la vez comprometiéndose a usar lanza, espada y brazo valeroso si fuere necesario conseguirlo por la fuerza, cuando «de grado» no se haga. Finalmente, subrayo el hecho de que la cita esté en el original, indicando explícitamente el título de la obra, el capítulo y, por fin, destacado el nombre del autor, Miguel de Cervantes Saavedra.

Viene, a continuación, la página de acotación de los personajes. Y al final de la página la indicación de que la acción transcurre en la capital de la isla de Tristiânia, «em tempos remotos» ${ }^{8}$.

El prólogo es metateatral, pareciendo insertarse en una cierta tradición, popular y bufonesca. A la entrada de una barraca se anuncia en «gordas letras» la farsa Dulcinéa ou a última aventura de D. Quixote y, junto a la taquilla, bajo «uma cavatina infernal», un personaje -Don Roberto, se presume que el dueño de la compañía, ciertamente el que en la lista de los personajes se nos presenta como «poeta satírico»- se dirige al público anunciándole la función como «a mais antiga farsa que tem feito rir e chorar» a todo el género humano. La presenta como la última aventura de la «asombrosa vida del famoso Don Quijote de La Mancha», la cual, por el hecho de ser precisamente la última, no pudo ser conocida por «el portentoso escritor» que la puso en libro, aventura ésta de la cual «o autor desta farsa» tuvo la fortuna de encontrar su relato en los papeles viejos de una notaría.

La convergencia con el texto cervantino empieza ya a desdoblarse en gestos múltiples. Además de la apropiación del personaje, nos encontramos, desde su misma génesis, con el recurso a procedimientos retóricos como el recién aludido manuscrito encontrado. En otro contexto, deberíamos ya preguntarnos a cuál de los autores inventados por Cervantes se está refiriendo Don Roberto, no ciertamente a aquél que, como sabemos, nos contó la muerte de su héroe. Así que, tal como otros habían hecho ya, a Don Roberto / Carlos Selvagem no les conviene la muerte de Don Quijote. Y se dan a sí mismos la ocasión de resucitarlo falsamente, para continuar las historias de sus hazañas, concluyo, parafraseando el final de 1615. Precisamente, entender las razones y objetivos, la necesidad y las circunstancias de este resucitarlo, aunque falsamente, guían, en gran medida, mi lectura de esta su «última aventura», señalando igualmente su destacada calidad literaria y teatral.

8. Citaré siempre la obra en su original portugués, exceptuando algún momento y siempre por razones que me parecerán claras o necesarias para el lector no portugués. 
Siguiendo los pasos de su modelo y matriz cervantina, el prólogo de Selvagem recurre a otros materiales tales como la explicitación de las intenciones del autor, el lenguaje y los ritmos de la frase... Así, por ejemplo, cuando se nos dice que $« \mathrm{O}$ autor pretende apenas divertir-vos - ao sizudo como ao leviano, ao grave como ao embusteiro, ao pobre como ao opulento, ao sábio como ao iletrado», afirmación paralela a la del pasaje del prólogo del Quijote de 1605, donde el «amigo» le dice al autor: «Procurad también que, leyendo vuestra historia, el melancólico se mueva a risa, el risueño la acreciente, el simple no se enfade, el discreto se admire de la invención, el grave no la desprecie, ni el prudente deje de alabarla».

También aquí se anuncia al espectador la acción. En este orden:

1. «aí veréis os amores do engenhoso Fidalgo com a perversa Florinda!»;

2. «aí vereis castigados os desvarios da ambição de corrigir este mundo!»;

3. «aí vereis, em resumo, a Razão a triunfar do Erro, e a Virtude confundir o Vício».

Destaco estas intenciones aquí anunciadas. Y estaremos atentos, en el desarrollo del argumento, para saber de quiénes son los desvaríos y la ambición de corregir este mundo, dónde está la Razón y dónde el Error, dónde la Virtud y dónde el Vicio, los cuales, según el autor, habrá que no confundir nunca.

Lo que sí veremos, desde muy temprano, es cómo este Don Roberto, que aquí presenta la representación de la obra (¿es él su autor, el poeta «satírico»?), va a tener en la misma un papel importante: será él quién incite al pueblo a la revuelta (esperando tener más tarde la gobernación en sus manos). Pero, siempre sobre él, veremos más cosas que nos han de desconcertar.

Finalmente, bien al contrario del autor del Quijote, que presentó su historia como una crónica historiográfica, dice éste en el prólogo que aquí se trata de una «fábula». Que, como tal fábula, aquí nada «hay de común con la vida real de los hombres». Y que «si por casualidad os pareciere tal, tenedlo por coincidencia o por vuestro propio anhelo». Es mi convicción que al lector -o al espectador- de 1944 (he conocido a alguno), sí ha de parecerle que mucho tiene en común con su vida y su tiempo bien reales y mucho con sus anhelos.

Veamos, pues, como se desarrolla la obra que se nos anuncia como una «Farsa heróica em 5 jornadas com 2 quadros e prólogo».

\section{LA PRIMERA JORNADA, EN LA PLAZA Y EN LA VENTA}

Primera acotación escénica: «pequena praça de cidade antiga». Una hospedería, que paso a llamar «venta» ya que ella sigue el modelo cervantino y, más tarde, va efectivamente a ser llamada «venta». Allí transcurrirá la mayor parte de la acción. Las primeras palabras que se escuchan en escena y que son las 
únicas de la primera escena son las de un sereno:-Raiou o dia, fregueses! Raiou hoje um claro dia!... ${ }^{9}$.

Y, luego, en la apertura de la escena II, escuchamos el nombre de la ciudad/ isla donde tiene lugar la acción: Tristiânia (que contrasta, nótese, con el «claro día» acabado de anunciar y que, según algunas lecturas, sería un neologismo formado por: triste Lusitánia). A su vez, la exclamación y la suspensión de la frase raiou hoje um claro día!... dialoga con la «neblina» del mito sebástico. Y su sentido mesiánico-profético será reforzado en las escenas siguientes, con esta otra frase, que escuchamos repetidamente en boca de otros personajes: -Atrás de tempos, tempos vêm!... ${ }^{10}$.

A través de la conversación de los personajes, entre ellos, marido y mujer, los dueños de la venta, nos enteramos que el día anterior Don Quijote estuvo en la isla, habiéndose enfrentado con el jefe de la policía, que esta mañana vemos venir con sus «alabarderos» en busca de «papeles» dejados por Don Quijote. El ventero oculta el «papel», mintiéndole al capitán, pero es a través de la lectura de este papel como escuchamos la voz de Don Quijote, aun antes de que éste aparezca en escena, un poco después, ya en la jornada II. Surge, aquí, la primera paráfrasis del texto cervantino, ya que en el papel, enunciado en primera persona por quien firma «Cavaleiro da Triste Figura», éste se presenta, entre otras palabras, como el que «à sua dama fêz voto de proteger os fracos e os aflitos, libertar os oprimidos, socorrer os desgraçados, castigar afrontas, desfazer agravos e combater toda a sorte de injustiças, violencias e tiranias», esto es, una simple y llana traducción del texto cervantino que bien conocemos. Y regístrese el comentario del hospedero cuando termina la lectura del «papel»:

\section{-Regala os bofes, mulher, ouvir tais coisas em favor do povo! [cursiva mía]}

Queda, pues, explicitada, desde el inicio, la relación entre el proyecto -el programa de acción- de Don Quijote y su interés para «el pueblo». A su vez, el capitán de la policía amenaza al alabardero en relación con los «papeles»: «se tornar a apanhar-te em flagrante trapaça, levar-te-ei ao pelourinho e ali te farei bailar por contumaz e rebelde contra a segurança do Estado» (p. 27). Antes aún de que se termine esta primera jornada, aparece en escena Sancho Pança (cena V, p. 37), cuya función en la obra trataré de profundizar más adelante. En la escena VI aparecen Bandurra, poeta ciego -que canta sus coplas «em louvor do Encoberto»- y Jocriz, una especie de escudero de Bandurra cuyo nombre evoca Jesucristo. (La $u$ en el lugar de la $a$ del mitificado poeta popular de las famosas coplas, Bandarra, parece ser, puede ser, un rasgo disfórico y ridiculizador.) Todos beben y brindan por o dia que vem perto, ese día anunciado, que todos esperan y dicen acercarse. 
Nos encontramos con una obra compleja, desde el punto de vista político-ideológico y ético, la cual presenta una complejidad correlativa en el uso de las figuras de Don Quijote y de su escudero también desde esa perspectiva. Destacaré, pues, algunos momentos que estimo muy significativos en la elaboración de esa complejidad. Ya en esta primera jornada tiene lugar un diálogo, en la escena VI, entre Don Roberto y Sancho Panza: tras escuchar las coplas de Bandurra sobre «el Encubierto», donde se habla de un caballero «que foi anunciado e não se deve nomear... que virá como um ladrão na noite... na manhã de nevoeiro», Sancho no entiende quién es este caballero al que aluden las coplas cantadas por Bandurra, un caballero que tiene la palabra «Libertad» inscrita en su blasón y que combate al otro, cuyo mote es «Injusticia», cuya ley es «Tiranía», un caballero que da al pueblo una victoria sobre aquel otro. Sancho no entiende qué tiene que ver la canción con el señor su amo y le pregunta a Bandurra: «-Ainda que mal pareça, senhor poeta, quem é esse mata-moiros lá da sua versalhada, e que tremendo combate ganhou ele nesta ilha?».

Tras la insistencia de Sancho en decirle al «señor poeta» que él sigue sin entender, éste le contesta: «-Pois não percebeste ainda, ó pipa de simplicidade, que esse nobre cavaleiro é o teu Senhor Dom Quixote?»

Ya aquí y a continuación, el autor va a echar mano de lo que parece ser la función de Sancho, que paso a llamar «desidealizadora» ${ }^{11}$. Don Quijote había tenido un enfrentamiento físico con el capitán de la policía. Las coplas de Bandurra lo convierten en héroe del duelo. Los otros dicen que, en el combate, vieron a don Quijote venciendo al tirano; Sancho dice que lo que él vio fue al tirano echando por tierra a Don Quijote, y a su amo salvado por el pueblo que viene a liberarlo de las manos del otro: «Então não vi eu também toda essa fantochada? Quem livrou meu pobre amo duma tareia foi todo o povo da ilha...». Don Roberto y el ventero le llaman mentiroso y mentecato y Sancho describe minuciosamente lo que vio, con sus ojos «mortais». Bandurra, usando la referencia crística, le acusa de traidor, comparándole con Pedro, que tres veces había negado a su Señor. Y solo Felícia, la ventera, reconoce que Sancho dice «la pura verdad». Pero los otros siguen acusándole de haberse «vendido a los tiranos». Y recurren a varias estrategias para convencerle.

Así, tenemos ya a Bandurra como mistificador (y a Don Roberto que se sirve de esa mistificación) versus Sancho Panza ${ }^{12}$, que ha visto lo ocurrido e insiste en decir cómo lo vio (molinos y no gigantes...). Sancho se resiste a admitir la homologación que los otros pretenden hacer y que convierte a Don Quijote en el Rey Encubierto. Le repiten las coplas del rey Dom Sebastião para que Sancho vea la analogía pero éste sigue contestando: «E que tem essa

11. Un análisis comparativo de esta «desidealización» de Sancho en las literaturas europeas nos mostraría resultados muy interesantes. Pero ésa es una tarea que sobrepasaría el propósito de este ensayo y que, en todo caso, yo enmarcaría en la original contribución de Kafka a la interpetación de la figura de Sancho (ver Abreu, 2011).

12. Por cierto, en la referida primera puesta en escena, interpretado por João Villaret, uno de los mayores actores del teatro portugués. 
cantiga que ver com o senhor meu amo?». Don Roberto intenta convencerle de que acepte esta versión, «a ti só deve importar a bela coroa de Conde», siguiendo, de nuevo, las señas de identidad cervantinas de Sancho. «Nunca mais dirás que o povo arrancou teu amo das unhas do capitão» (p. 47), le ordena. Pero Sancho llamará a todo esto «patranhas» y «endróminas». Y durante toda la escena, en sus hablas aparece fielmente caracterizado, también en su versatilidad psicológica, de acuerdo con el libro de Cervantes (al revés de lo que tantas veces ocurre en las recreaciones quijotescas de la época, donde responde más bien a los tópicos que la crítica incesantemente repite sobre él y que incluso los socialrealistas, a pesar de haberle elegido como bien preferible a su amo, no dejaron de repetir). En una de las acotaciones, se lee: «Sancho (digno)».

Llegados, pues, al final de la primera jornada, y aun antes de que Don Quijote haya aparecido directamente en escena, tenemos ya todos los elementos configuradores de la sebastianización del hidalgo /caballero cervantino («É que já ninguém duvida, bruto, que ele é o Rei Encoberto!», le dice Don Roberto a Sancho). Tenemos, asimismo, la información de que él está en la isla para salvar al pueblo de la tiranía de los gobernantes, a la vez que, como escucharemos al principio de la segunda jornada, su presencia surge asociada a la profecía anunciada en las coplas de Bandarra. Y también que, en una (posible) lectura anti-sebastianista de la obra, Sancho resultaría ser una vía para el desenmascaramiento del mito sebastianista.

La primera actuación directa de Don Quijote, en la jornada II, se concreta en un discurso que parafrasea su elogio de los siglos dorados, aquel tiempo en el que «tudo era próprio e comum. Nenhuma barreira se erguia à igualdade dos homens...» (esc. IV). En una reseña a la publicación del Teatro Completo de Carlos Selvagem se escribió no hace mucho que la pieza «constitue um encontro feliz dos tempos passados e da obra de Cervantes com o ideário igualitário do Autor» ${ }^{13}$.

\section{EL DESARROLLO DE LA FARSA HEROICA}

¿Que va, entonces, a ocurrir en las jornadas siguientes? ¿Dónde está esa Dulcinea anunciada en el título?

Para eliminar a Don Quijote, el bando de los tiranos va a encargar a Florinda, sobrina de uno y amante de otro, a que lo seduzca, presentándose tras la máscara de Dulcinea. Empieza ella su acción a mitad de la obra. Y en un primer diálogo con Sancho, a quien intenta manipular para convencer a su amo de que ella es Dulcinea, de nuevo éste reafirma su función que aquí llamo «desidealizadora» y desmitificadora. Cuando aquella le dice que es Dulcinea, él contesta: 
-Não me faça mais labrego do que eu já sou!... Dulcinea foi a alcunha que ele pôs a uma porqueira lá dos meus sítios, que nem de vista a conhece... E ele mesmo só a viu de longe, umas quatro vezes... (Jorn. 3, escena XI).

También en boca de Sancho surge uno de los mitemas sebastianistas aquí usados en la sebastianización de Don Quijote, la isla, ya que, para ayudar a Florinda, convenciendo a su amo de que ella es Dulcinea, tendría ésta que «chegar a convencê-lo de que viveu encoberto um ror d'anos numa ilha», le dice el escudero. Al final de esta tercera jornada, Don Quijote ya está rendido a Florinda/Dulcinea. Sin embargo, a pesar de que intenten comprar a Sancho su ayuda, prometiéndole bienes materiales (siguiendo el tópico del «materialismo» de Sancho) éste desconfiará siempre de que ahí «há marosca!», artimaña o engañifa bien urdida.

Por otro lado, utilizando a Don Quijote como cebo «para inflamar esse povo e alimentar-lhe a esperanza»-como explícitamente reconoce Don Roberto-, el auto-erigido líder de la conspiración y de la Junta de Salvación Pública del bando revolucionario, prepara ya la traición para eliminar a Don Quijote cuando asuma la gobernación. Y así es. Llegado el momento de la victoria, aquél expulsa a Don Quijote y reintegra a los anteriores tiranos en su gobierno. A su vez, el pueblo que antes había aplaudido a Don Quijote, aplaude ahora al nuevo gobernante y apoya su acción de expulsión del caballero. Solo Florinda, que mientras tanto sufre un proceso de quijotización, no acepta ser reintegrada y prefiere morir en la hoguera.

En la quinta jornada, constituida ésta por los anunciados «dois cuadros», Don Roberto, con el poder ya en las manos, juzga a Don Quijote, Bandurra, Sancho y Florinda, en tribunal popular y soberano. Ante el cambio de actitud, que él no entiende, Don Quijote les pregunta: «Que queredes a D. Quixote, gente descomunal e bárbara?».

Y no cabe duda. A pesar de algunas voces discordantes, esa gente «descomunal e bárbara» votará por mayoría la expulsión de Don Quijote por «velho, louco varrido e estrangeiro» (por extranjero, ¿aquí, pues ya des-sebastianizado?), acusado de la «burlesca artimanha» de haber convencido a Bandurra de encarnar en él «a profecia da volta do Encoberto». Y la multitud «em delírio» aclama a Don Roberto y su «sabedoria».

Al final, caballero y escudero, despojados de sus trajes/máscaras sebastiánicos, siguen enteros en sus señas de identidad cervantinas. Y sin contaminaciones foráneas, apetece decir. Así, Sancho quisiera ver a su amo, «iracundo, como tantas vezes vi», salvar a Florinda de la hoguera; pero éste sabe que «Mais vale sonhá-la [a Dulcinea] que havê-la». (¡Mejor soñarla que tenerla!) Y que, «desfeito o encantamento, logo os inimigos da alma-Diabo e Melancolianos quebram de todo o ânimo para correr esta louca aventura que é a vida!»

Largo tiempo nos ocuparía analizar y dar razones para este final, sin duda desconcertantemente disfórico, desde los puntos de vista ideológico, ético, político y existencial. ¿O será que también éste, el final, es, en parte, heredero del final del libro de Cervantes, además de ser hijo de los tiempos en los que se escribió esta obra de teatro? ¿Y por qué el autor pone tan miserable 
papel en manos de un poeta satírico? «Eu sou um poeta, um artista!», dice él, precisamente cuando hace el papel de denunciador-traidor de la revuelta popular, ante los tiranos (jornada $4 .^{\mathrm{a}}$, esc. IX).

Hasta aquí, el primero «quadro» de la última jornada. Pero el segundo «quadro» y final de la obra nos ofrece un nuevo aliento. Don Quijote de La Mancha, el extranjero, vuelve «a sus tierras de España». Sin embargo, en la isla se escucha, de nuevo, la voz del sereno que anuncia, tal como al inicio de la obra, el rayar de un claro día. Aquí, queda D. Jocriz de Tristiânia, quien, recogiendo la semilla quijotesca, ahora, de nuevo bajo el yugo de la tiranía, retoma las armas y la espada y repite las palabras programáticas de Don Quijote y de su tarea caballeresca, su promesa de «alevantar os humildes, libertar os oprimidos, socorrer os agravados e castigar toda a sorte de injustiças, violencias e tiranias». ¿Por eso y para eso había este autor falseado el final del héroe cervantino e ignorado su muerte? ¿Es éste el heroísmo que ha de enfrentarse a la farsa de los traidores?

Para terminar, vuelvo a la recepción contemporánea de la representación de la pieza sobre la cual adelantaba yo algunos apuntes al inicio de este ensayo. Germán Gan Quesada investigó los artículos y reseñas publicados en la época y, a partir de ellos, concluyó, lógicamente, repito sus palabras, que «la crítica teatral no se mostró demasiado convencida del logro de las intenciones simbólicas del argumento de Selvagem -y de su probable dimensión de crítica política al régimen dictatorial de Salazar...-》 (Gan Quesada, 2007: 381).

Entiendo que alguien que no vivió, felizmente, bajo una dictadura, y me alegro mucho por ello, tome a la letra aquellas reseñas de los primeros años de la década de los 40 en Portugal. Pero quienes sí vivieron bajo esa dictadura saben que ningún periódico o crítico podría atreverse a mostrar «el logro de las intenciones simbólicas» $-\mathrm{y}$, sin cualquier asomo de duda, políticas- del argumento de la obra y de su desarrollo. De hecho, es fácil deducir, en Lusitânia, el tristemente famoso «lápiz azul» de la censura salazarista no habría permitido su publicación y ni siquiera había periódico donde ello se publicase. Tanto los periódicos como los críticos invocados eran, como por allá se decía, «del régimen». En contrapartida, en la ya citada evocación, breve y sintética, de la obra de Carlos Selvagem, donde lo considera como miembro «da geração de autores que, depois da primeira guerra mundial, tentaram sacudir o nosso teatro da inércia em que vegetava», Luiz Francisco Rebello, refiriéndose a la pieza como «um dos mais belos espectáculos montados no Teatro Nacional pela Companhia de Amélia Rey-Colaço», reproduce palabras de Luís Forjaz Trigueiros que la aclamó como «uma grande tentativa de teatro sério e autêntico, no chocho Carnaval em que vive há tantos anos o teatro português», afirmando que «opera brilhantemente a síntese do quixotismo com o sebastianismo para dar expressão cénica ao "sonho do homem que desde o fundo das idades sofre o combate por um ideal de libertação, de redenção, de justiça social"» ${ }^{14}$.

14. Ver nota 7. 


\section{BIBLIOGRAFÍA CITADA}

Abreu, Maria Fernanda de (1994a). «Dom Quixote "sebastianizado" e Dom Sebastião "quixotizado"», en Cervantes no Romantismo Português. Cavaleiros Andantes, Manuscritos Encontrados e Gargalhadas Moralíssimas. Prólogo de Claudio Guillén. Lisboa: Editorial Estampa, imprensa universitária, pp. 99-105.

Abreu, Maria Fernanda de (1994b). «O apropriador apropriado: a sebastianização de Dom Quixote». Ponencia presentada al IV Congresso ABRALIC, de 1 Associação Brasileira de Literatura Comparada, realizado en la Universidad de São Paulo (Brasil), del 31 de júlio al 3 de agosto.

Abreu, Maria Fernanda de (1996). «Labirintos da identidade: de como um fidalgo castelhano-manchego foi chamado a salvar a pátria portuguesa (da Literatura Comparada ao Fado Lusíada)», Revista da Faculdade de Ciências Sociais e Humanas. Identidade, Tradição e Memória, 9 (Actas do $1^{\circ}$ Colóquio Interdisciplinar da F.C.S.H), pp. 187-199.

Abreu, Maria Fernanda de (2011). «Sancho, su diablo y los tapices por el revés: la heterodoxia de Kafka», en Carmen Rivero Iglesias (ed.), Ortodoxia y heterodoxia en Cervantes. Alcalá de Henares: Centro de Estudios Cervantinos, pp. 287-297.

Ribeiro Colaço, Thomaz ([1953]). D. Quichote - Rei de Portugal. Lisboa: Edições SIT.

Gan Quesada, Germán (2007). «Variaciones sobre el tema cervantino en la música de la familia Halffter», en Begoña Lolo (ed.), Cervantes y el Quijote en la música: estudios sobre la recepción de un mito. Alcalá de Henares: Centro de Estudios Cervantinos, pp. 373-398.

Oliveira, Fernando Matos de (2000). Reseña crítica a Teatro Completo. Com peças inéditas de Carlos Selvagem, Revista Colóquio/Letras. 57, 158. Lisboa: Fundação Calouste Gulbenkian, pp. 418-419.

Oliveira, Vitor Amaral de (2002). Sebástica. Bibliografia Geral sobre D. Sebastião. Coimbra: Biblioteca Geral da Universidade.

Pessoa, Fernando (1986). El regreso de los dioses. Barcelona: Seix Barral.

Rebello, Luiz Francisco (1991). «Evocação de Carlos Selvagem (1890-1973)», Revista Colóquio/Letras, 119. Lisboa: Fundação Calouste Gulbenkian, pp. 194-195.

Selvagem, Carlos (1943). Dulcinéa ou a ultima aventura de dom Quixote. Lisboa: Editorial Aviz.

Recibido: 5 de noviembre de 2012

Aceptado: 9 de diciembre de 2013

\section{Resumen}

En el presente artículo se comenta la obra del dramaturgo portugués Carlos Selvagem, Dulcinéa ou a última aventura de Dom Quixote, una "farsa heroica» representada en el Teatro Nacional Dona Maria, en Lisboa, en enero de 1944, con escenarios de Almada Negreiros y música de Ernesto Halffter. Bajo una perspectiva comparatista, se analiza el texto publicado en libro, en el ámbito del estudio de las recreaciones del Quijote, contextualizando, en los planos político e ideológico, la «sebastianización» del héroe cervantino aquí presentada, interpretando su desarrollo argumental y observando sus relaciones con el modelo cervantino.

Palabras clave: Don Quijote; literatura portuguesa; teatro. 
Title: 1943. Don Quixote Sebastianised. In a Forlorn Place in Europe, which the Author Attempted to Call Tristiania.

\begin{abstract}
This article comments the work of the Portuguese playwright Carlos Selvagem, Dulcinéa ou a última aventura de Dom Quixote, a Heroic Farce represented at the Teatro Nacional Dona Maria, in Lisbon, on January 1944, with settings by Almada Negreiros and music by Ernesto Halffter. From a comparative perspective, and regarding the study of the Quixote's recreations, the text published in the book is analyzed, contextualizing, in both political and ideological aspects, the «sebastianization» of the Cervantes' hero presented here, interpreting it's development concerning the plot, and observing its relationship with Cervantes' model.
\end{abstract}

Key words: Don Quixote; Portuguese Literature; Theater. 